\title{
Św. Izydor z Sewilli \\ O WINOROŚLI \\ (Etymologiae XVII 5: De vitibus)
}

\section{WSTĘP}

Etymologie św. Izydora z Sewilli (ok. 570-636) w ciągu wielu stuleci były najbardziej czytanym po Biblii dziełem chrześcijańskiego Zachodu ${ }^{1}$. Liczne pokolenia Europejczyków czerpały $z$ nich wiadomości o wszystkich istniejących wówczas naukach: od gramatyki po teologię, od muzyki po medycynę. Oczami ich autora widziano odległe kraje, kosztowne minerały, egzotyczne zwierzęta i rośliny². Księga XVII tej encyklopedii zatytułowana De agricultura zawiera informacje dotyczące historii uprawy ziemi i literatury rolniczej (rozdział I), rolnictwa i uprawy winorośli (rozdziały II-V) oraz poszczególnych roślin, zarówno uprawnych, jak też dziko rosnących; leczniczych, jadalnych, ozdobnych, wykorzystywanych do sprawowania pogańskich kultów (rozdziały VI-XI). W rozdziale I Biskup Sewilli wylicza imiennie głównych autorów starożytnej literatury rolniczej, nie wymieniając ich dzieł (Hezjod, Demokryt z Abdery, Kartagińczyk Magon) ${ }^{3}$ i lacińskiej, która mogła na niego bezpośrednio wplywać, a mianowicie: Marka Porcjusza Katona (234-149) ${ }^{4}$, Marka Terencjusza Warrona (116-26) ${ }^{5}$, epickiego poetę Wergiliusza (70-19) ${ }^{6}$, żyjących za

\footnotetext{
${ }^{1}$ Por. J. Fontaine, Introduction, w: Isidore de Séville, Traité de la nature, ed. J. Fontaine, Bordeaux 1960, 19.

${ }^{2}$ Por. J. Fontaine, Chrześcijańska literatura tacińska. Rys historyczny, tlum. J. Słomka, Tarnów 1997, 178-180; P. Riché, Edukacja i kultura w Europie Zachodniej (VI-VIII wiek), thum. M. Radożycka-Paoletti, Warszawa 1995, 303-313; M. Banniard, Geneza kultury europejskiej V-VIII wieku, tium. A. Kuryś, Warszawa 1995, 142-146.

${ }^{3}$ Por. R. Reitzenstein, De scriptorum rei rusticae, qui intercederunt inter Catonem et Columellam deperditis, Berlin 1884, 48; J. Heurgon, L'agronome carthaginois Magon et ses traducteurs en latin et en grec, „Comptes Rendus de l'Académie des Inscriptions et Belles-Lettres” (1976) 441-456.

${ }^{4}$ Por. jego De agricultura, thum. S. Łos; M.P. Cato, $O$ gospodarstwie wiejskim, BN II 103, Wroclaw - Kraków 1956.

${ }^{5}$ Por. jego De re rustica, thum. J. Mikołajczyk: Marek Terencjusz Warron, $O$ gospodarstwie rolnym, Wrocław 1991.

${ }^{6}$ Por. jego Georgica I-IV, tłum. A.L. Czerny: Wergiliusz, Bukoliki i Georgiki, Warszawa 1956.
} 
cesarza Tyberiusza Korneliusza Celsusa ${ }^{7}$ i Juliusza Attyka - autora zaginionej monografii o winorośli ${ }^{8}$, Kolumellę (I wiek) ${ }^{9}$ oraz Rutiliusza Emilianusa Palladiusza (IV wiek) ${ }^{10}$. Izydor nie wymienia tu natomiast Pliniusza Starszego (2379) ${ }^{11}$ ani komentatora Georgik Wergiliusza - Serwiusza ${ }^{12}$, z których obok Kolumelli i Palladiusza bez wątpienia korzysta1 ${ }^{13}$.

Obecnie prezentujemy pierwsze thumaczenie na język polski rozdziału $\mathrm{V}$ poświęconego winnej latorośli. Na jego wstępie Izydor wspomina początki uprawy winorośli (w. 1), następnie opisuje poszczególne części winnego krzewu (ww. 2-14), wymienia liczne odmiany rośliny, klasyfikując je na przeznaczone do jedzenia (ww. 15-17), wykorzystywane do wyrobu wina (ww. 18-26) oraz zasługujące na uwagę ze względu na urodzajność (ww. 27-29). Zamyka rozdział bardzo pobieżnym omówieniem głównych czynności pielęgnacyjnych, których wymaga uprawa winorośli (ww. 30-33). Łatwo zauważyć, że w jego strukturze Biskup Sewilli zachował porządek listy winorośli przedstawiony przez Kolumellę, a w niektórych miejscach (w. 28) jego tekst jest wprost paralelny do tekstu starożytnego agronoma ${ }^{14}$. Warto tu też dodać, że w izydoriańskiej relacji o winorośli można dostrzec analogiczne miejsca $z$ III homilii Heksaemeronu św. Ambrożego $(† 397)^{15}$, choć trudno przypuszczać, by Biskup Sewilli korzystał bezpośrednio w tym wypadku z komentarza Biskupa Mediolanu. Opisując winorośl Izydor pozwala sobie na krótkie dygresje o zjawisku monodyftongizacji „au" w „o" (w. 4) oraz nazwach pierwszych, bądź glównych i pochodnych, czyli derywatach (w. 9). Wierny obranej przez siebie metodzie, dochodzi do istoty opisywanych przedmiotów, zjawisk i działań poprzez etymologie ich nazw ${ }^{16}$.

\footnotetext{
${ }^{7}$ Por. jego zaginione De agricultura I-V przez Kolumellę i Pliniusza w Historia naturalis (por. księgi: XIV-XV, XVII-XIX).

${ }^{8}$ Por. H. Bardon, La littérature latine inconnue, II, Paris 1956, 140-141.

${ }^{9}$ Por. jego De re rustica I-XII oraz De arboribus, tłum. I. Mikolajczyk: Lucjusz Moderatus Kolumella, $O$ rolnictwie, t. 1 (ks. I-VI), t. 2 (ks. VII-XII oraz $O$ drzewach), Wrocław 1991 i Toruń 1991.

${ }^{10}$ Por. jego Opus agriculturae I-XIII, De veterinaria medicina (XIV), Carmen de institutione (XV: O szczepieniu) = Palladius, Traité d'agriculture . Texte établi, traduit et commenté R. Martin, Paris 1976.

11 Por. jego Historia naturalis I-XXXVII, thum. J.T. Zawadzcy: Pliniusz, Historia naturalna (Wybór), BN II 128, Wroclaw - Kraków 1961.

12 Por. Servii Grammatici qui feruntur in Vergillii carmina commentarii, I-II, Leipzig 1881.

13 Por. J. André, Introduction, w: Isidore de Séville, Étymologies XVII, s. 3-16.

14 Winorośli i jej uprawianiu Kolumella poświęcil III-IV oraz część (rozdz. 18-34) XXI księgi swego traktatu $O$ rolnictwie, także połowę (rozdz. 1-18) $O$ drzewach, w przekładzie I. Mikołajczyka zob. t. 1, s. 61-121 oraz t. 2, s. 190-204.

15 Por. De agricultura 5, 2 (Hexaem. III 12, 49) i 5, 10 (Hexaem. III 12, 52 i 14, 60).

${ }^{16}$ Por. M. von Albrecht, A History of Roman Literature from Livius Andronicus to Boethius, New York 1997, 604-609; R. Collins, Europa wczesnośredniowieczna 300-1000, tłum. T. Szafrański, Warszawa 1996, 168.
} 
Największą trudność nastręcza oddanie zawartych w tekście nazw odmian winorośli. Liczni tłumacze poprzestają na ich transliteracji oraz wyjaśnieniu w językach nowożytnych. Pamiętając jednak, że celem przekładu jest maksymalne przybliżenie czytelnikowi treści zawartych w oryginale oraz umożliwienie mu, o ile jest to osiaggalne, odczuwania tekstu w ten sam sposób, w jaki odczuwałby go nosiciel języka oryginału postanowiliśmy przetłumaczyć wszystkie nazwy, które się da przetlumaczyć, pozostawić natomiast bez thumaczenia nie mające $w$ polskim dokładnych odpowiedników o podobnym bogactwie znaczeniowym (elbolae, inerticula) oraz nazwy nie będące do końca jednoznaczne nawet dla Rzymianina, jak chionia i basilisca. Nazwy odmian pochodzące od nazw własnych podajemy w wersji spolszczonej.

Mimo popełnionych nieścisłości, często naiwności, a w każdym razie nienaukowości - w świetle dzisiejszego rozumienia pojęcia nauki - wywodów Izydora, tekst wzbudza zainteresowanie, gdyż stanowi cenny przykład recepcji antycznej wiedzy agrarnej i botanicznej. Zasługuje na uwagę również dlatego, że w ciągu stuleci kształtował wyobrażenia pokoleń czytelników o tym, jaką drogę przebywa wino od sadzonki do pucharu wypełnionego rozkosznie smakującym płynem.

\section{WYDANIA TEKSTU}

J.P. Migne, Paris 1850, PL 82 602-606.

W.M. Lindsay, Etymologiarum sive Originum libri XX, Oxford 1911.

J. André, Étymologies. Livre XVII: De l'agriculture, texte établi, traduit et commenté, Paris 1981, 51-65.

J. Oroz Reta, Etimologias. Edición bilingüe, II, BAC 434, Madrid 1983, 330-334.

\section{PRZEKEADY NOWOŻYTNE}

Angielski:

W.M. Lindsay, Etymologiarum sive Originum libri XX, Oxford 1911.

Francuski:

J. André, Étymologies. Livre XVII: De l' agriculture, Paris 1981, 51-65. Hiszpański:

J. Oroz Reta, Etimologias, II, Madrid 1983, 331-334.

\section{BIBLIOGRAFIA}

E. Dressel, De Isidori Originum fontibus, RFIC 3 (1875) 207-268; R. Billiard, Le vigne dans l'antiquité, Lyon 1913; J. André, Contribution au vocabulaire de la viticulture: les noms des cépages, REL 30 (1953) 126-156; M. Sergeenko, Očerki po 
sel'skomu hoziajstvu Drevnej Italii, Moskva 1958; J. Opelt, Christianisierung heidnischer Etymologien, JACh 2 (1959) 70-85; J. Fontaine, Isidore de Séville et la culture classique dans l'Espagne visigothique, I-III, Paris 1959 i 1983; tenże, Isidore de Séville, Traité de la nature, Bordeaux 1960; R. Schroeter, Studien zur varronischen Etymologie, Wiesbaden 1960; I. Opelt, Etymologie, RACh VI 797-844; M. Reydellet, La diffusion des „Origines” d'Isidore de Séville au haut Moyen Age, "Mélanges de l'École Française de Rome" 78 (1966) 383-437; J. Kolendo, Les esclaves employés dans les vignobles de l'Italie antique, „Acta Conventus Eirene” 11 (1968) 33-40; J. Fontaine, Cohérence et originalité de l'Étymologie isidorienne, w: Homenaje a Eleuterio Elorduy, Bilbao 1978, 113-144; G. Gasparotto, L'agricoltora nelle „Etymologiae” di Isidoro di Siviglia, „Economia e Storia” 1978, 197-220; Z. Podbielkowski, Stownik roślin użytkowych: polski, taciński, angielski, francuski, niemiecki, rosyjski, wyd. 4, Warszawa 1980; J. André, Introduction, w: Isidore de Séville, Étymologies XVII, Paris 1981, 3-19; M.C. Diaz y Diaz, Introducción general a San Isidoro de Sevilla, w: Etymologías, éd. J. Oroz Reta, Madrid 1982, 1-257, spec. 162-214 (Las Etymologías); M. Gómez Lozano, El léxico de la planta de la vid en las „Etimólogias" de San Isidoro de Sevilla, „Helmantica” 40 (1989) 293-301 (XVII 5, 1-14).

\section{PRZEKŁAD*}

1. Jako pierwszy zaczął uprawiać winorośl Noe, w czasach nie znających jeszcze żadnej ogłady. Grecy natomiast za wynalazcę winorośli uważali Libera, dlatego też poganie po śmierci uznali go za boga ${ }^{1}$. 2 . Winorośl (vitis) nosi taką nazwę, gdyż ma siłę (vim), która pozwala jej szybko zakorzeniać się. Inni uważają, że została tak nazwana, ponieważ za pomocą wstęg (vittis) jej gałęzie są ze sobą splatane oraz wiązane do pobliskich drzew, na które się wspinają. Albowiem gałązki winnej latorośli są z natury giętkie, tak że wszystko, czego się chwycą, ściskają jakby ramionami. 3. Dzikie wino to winorośl, która rośnie na obrzeżach pól, stąd też nazywana jest dzikim winem (labrusca) od krawędzi (labrum) i krańców pól. 4. Pień (codex) został tak nazwany od caudex (= codex); starożytni bowiem podobnie mówili clodum zamiast claudum ${ }^{2}$. 5. Gałąza (sarmentum) nosi taką nazwę od sadzenia (serere), to jest od serimentum

* Przekładu dokonano na podstawie wydania krytycznego J. André, Étymologies: livre XVII, Paris 1981, 51-65.

1 Prezentując początki uprawy winorośli Izydor odwołuje się, jak widzimy, zarówno do przekazu biblijnego $(\mathrm{Rdz} 9,20)$, jak też do tradycji antycznej. Warto zwrócić uwagę, że bez cienia wahania utożsamia on lacińskiego Libera z czczonym przez Greków Bachusem; zob. Tertullianus, Apologeticum 11, 8: „propterea Liber deus quod vitem demonstravit”.

${ }^{2}$ W IV wieku Serwiusz akcentowal poprawnosć używania klasycznych form $z$ dyftongami (Georg. II 30). W czasach Izydora właśnie one, a nie uznawane niegdyś za wulgarne, pochodzące $\mathrm{z}$ dialektow formy monodyftongizowane, wymagały wyjaśnienia, por. J. Safarewicz, Zarys historycznej gramatyki języka tacińskiego, Warszawa 1953, 48-49; zob. J. André, Étymologies XVII 5, s. 51, n. 84: ,obydwie formy są równie starożytne: caudex poświadczany jest od Katona, a codex od 
(sadzenie). Pęd (malleolus) to najmłodsza gałązka, która pojawiła się na ubiegłorocznej gałęzi, nazwana tak $z$ powodu podobieństwa do młotka (malleus), gdyż w tej części, w której wyrasta ze starej gałęzi, ze wszystkich stron poszerza się przybierając wygląd młotka ${ }^{3}$. 6. „Eunuchami” (spadones) zwą gałązki nie przynoszące plonu, dlatego że, podobnie jak oni, są pozbawione owoców i dotknięte niepłodnością ${ }^{4}$ 7. „Strzałą” (sagitta) wieśniacy nazywają najmłodszą część gałązki, czy dlatego, że oddala się od matki i niejako wystrzeliwuje, lub też dlatego, że cienkością wierzchołka przypomina ten pocisk ${ }^{5} .8$. Odrosty winnej latorośli i krzaków nazywa się biczami (flagella), ponieważ poruszają je podmuchy wiatru (flatus). 9. Owocująca gałązka winorośli, która jest miękka, wydobywa i rodzi z najmłodszych gałązek owoce, dlatego też wieśniacy nazywają tę część winorośli palmes. Palmes bowiem jest zdrobnieniem pochodzącym od palma (dłoń). Nazwa zaś palma jest nazwą pierwszą, zwaną też główną, gdyż z niej powstają derywaty. 10. Liście winnej latorośli (pampinus) chronią ją w czasie chłodów i upałów oraz bronią przed wszelką szkodą. Dlatego też w niektórych regionach są one przycinane, aby zarówno dopuszczały słońce pozwalające owocom dojrzewać, jak też dawały cień. Zwane są niekiedy pampini, ponieważ zwisają (pendeant) z gałązki. 11. Wąsiki (caprioli) zostały tak nazwane, gdyż łapią (capiant) drzewa. Są to bowiem kędziorki, czy też haczyki, którymi winorośl czepia się i zawisa na drzewach; ufna w ich wsparcie może lekceważyć wiatry i burze, rozrasta się wysmukła niczym nieskrępowana, a jej grona nie opadają, lecz zachowują jagody. 12. Corimbi to pierścionki, które przytrzymują i chwytają najbliższe przedmioty, aby zbyt rozrzuconych gałęzi nie zniszczyły podmuchy wiatru ${ }^{6} .13$. Winogrona (uvae) zostały tak nazwane, gdyż wypełnione są od wewnątrz wilgotnym (humidum), gęstym sokiem. Albowiem humidum nazywamy coś, co ma płyn od zewnątrz, uvidum - od wewnątrz. 14. Jagoda. Grono (botrus) ${ }^{7}$. Winna jagoda jest częścią grona, które po grecku nazywa się botrio.

Plauta. Dla claudus zob. Etymologiae XII 3, 2: «Antiqui autem soricem sauricem dicebant, sicut et clodum claudum»".

${ }^{3}$ Por. Columella, De re rustica III 6, 3 .

"Por. tamże III 10,15: „eiusmodi surculos, qui nihil tulerint, spadones appellant”.

5 Por. tamże III 17, 2: ,Sagittam rustici vocant novissimam partem surculi...”.

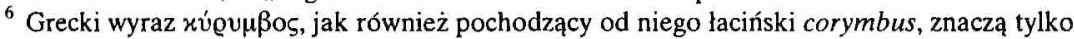
i wylącznie kiść, czy też pęk - kwiatów, liści, gałązek, owoców, w łacinie kościelnej używa się go również w znaczeniu przenośnym na oznaczenie frędzli szat. Opisując corimbi Izydor mówi właściwie 0 wąsikach, zaprezentowanych już w wierszu 11 pod nazwą caprioli. Skąd pochodzi jego błędne przekonanie, nie wiadomo, por. André, Étymologies XVII 5, s. 54, n. 96.

${ }^{7}$ Smierć nie pozwoliła Izydorowi dokonać ostatecznej redakcji Etymologii. O braku dopracowania i wygładzenia encyklopedii świadczą pojawiające się w niej tu i ówdzie wymienione w sposób konspektowy, jak tu, nazwy części i poszczególnych gatunków roślin, por. na przykład księgę XVII 9, 102; 11, 5-9; zob. także J. Madóz, Isidoro de Sevilla. Semblanza de su personalidad literaria, León 1960, 57; J. Fontaine, Introduction, w: Traité de la nature, dz. cyt., s. 13. 
15. Pewne odmiany winogron zwiemy podmiejskimi, gdyż sprzedawane są w mieście do spożycia jak owoce; wyróżniają się zarówno wyglądem, jak też przyjemnym smakiem ${ }^{8}$. Należą do nich: wczesne, mające twardą skórkę, purpurowe, paluszki ${ }^{9}$, rodyjskie, libijskie, ogniste ${ }^{10}$, wieńcowe ${ }^{11}$, trzystopowe $^{12}$, uncjowe $^{13}$, cydońskie ${ }^{14}$. Przez całą zimę mogą być przechowywane winogrona wenikulskie oraz numizjańkie ${ }^{15}$. 16 . Wczesne winogrona (praecoquae) są tak zwane, ponieważ szybko dojrzewają, dlatego że słońce czyni je dojrzałymi (coquantur) przed wszystkimi innymi. Grecy nazywają je zajęczymi (lageos), ponieważ podążają do dojrzałości szybko jak zając ${ }^{16}$. 17. Purpurowe - nazywane są tak dla ich koloru, uncjalne dla wielkości, paluszki dla długości, wieńcowe dla okrągłości. Rodyjskie i libijskie otrzymały swoje nazwy od regionów.

${ }^{8}$ Następujące wyliczenie odmian winorośli jest utkane $\mathrm{z}$ fragmentów traktatu o rolnictwie (III 2, 1-2) Kolumelli, przytaczanych niekiedy dosłownie, niekiedy w formie znacznie skróconej - taki jest w końcu wymóg kompilacji, por. J. André, Les noms de cépages, REL 30 (1953) 136-137; tenże, Etymologies XVII 5, s. 56, n. 99.

${ }^{9}$ Dactili: J. André proponuje tłumaczyć tę nazwę jako „daktyle” (por. przekład: Étymologies

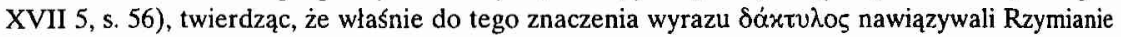
mówiąc o wspomnianej odmianie winogron. Pliniusz jednak pisze, że „dactylides vites ... dictae a gracilitate digitali" (Historia naturalis XIV 4). Na Krymie istnieje odmiana winorośli zwana paluszkami damy (дамские пальчики) mająca długie jagody o cienkiej skórce.

${ }^{10}$ Cerauniae. Łacińskie ceraunius pochodzi od xع@aúvios (odnoszący się do błyskawicy). Tę nazwę nadano wspomnianej odmianie winorośli, gdyż dostrzegano w jej kolorze podobieństwo do błyskawicy czy czerwieni ognia. Starożytni autorzy, między innymi Pliniusz Mlodszy, Solin, Martianus Kapella opisywali również kosztowny kamień czerwonawego koloru o tej nazwie (gemma ceraunia). Wierzono, że spadał on na ziemię w czasie burzy wraz z błyskawica, por. A. Forcellini, Lexicon Totius Latinitatis (dalej cyt. LTL), II, Prati 1861, 147; zob. także I. Dvoreckij, Latinskorusskij slovar', Moskva 1996 134.

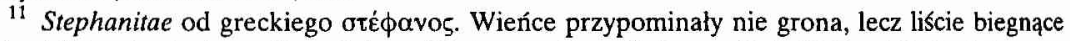
między kiściami tej winorośli, podaje za Pliniuszem Forcellini, por. LTL V, Prati 1871, 630.

12 Tripedianae. Pliniusz wyprowadza tę nazwę od wysokości winorośli. Rzymska stopa wynosi $29,57 \mathrm{~cm}$. Biorąc pod uwage, ze winna latorośl osiąga do $50 \mathrm{~m}$ długosci, można pokusić się o stwierdzenie, że była to jedna z mniejszych odmian, por. LTL VI, Prati 1875, 183; zob. także B. Zemanek, Winorosil, w: Encyklopedia biologiczna, XI, Kraków 2000, 338-339.

${ }^{13}$ Unciariae. Rzymska uncja równa się 27,3 g. Pliniusz podaje, że winorosl ta uzyskała tę nazwę dla swoich wielkich i ciężkich kiści. Należy więc przyjąć, że tyle ważyła jedna winna jagoda, albo, co jest bardziej prawdopodobne, że nazwa została nadana w sposób przenośny i oznaczała tyle, co duże winogrona, por. LTL VI, Prati 1875, 388-389.

${ }^{14}$ I. Mikołajczyk uważa, że ta winna latorosl zwana tak była dia jej podobieństwa do pigw (mala cidonea), czy też dla jej pochodzenia z Cydonii na Krecie, por. Lucjusz Juniusz Moderatus Kolumella, O rolnictwie (III 2, 2), thum. wstęp i komentarz I. Mikołajczyk, I, Wrocław 1991, s. 63, n. 14 ..

${ }^{15}$ Zdaniem Forcelliniego, nazwa ta pochodzi od imienia jednego z przedstawicieli rodu Numizjuszy (Numisii), por. LTL IV 316; por. Columella III 2, 2 i 27; André, Les noms de cépages, s. 134.

${ }^{16}$ Zając po grecku nazywa się $\lambda \alpha \gamma \omega ́$ s. Wergiliusz wyraźnie rozróżniał te dwie odmiany winogron, por. Georgiki II 93, a także komentarz Serwiusza ad locum. Inne wersje pochodzenia tej nazwy przytacza J. André, Étymologies XVII S, s. 56, n. 100; tenże, Les noms de cépages, s. 181. 
Czerwonawe winogrona zostały tak nazwane, ponieważ ich miąższ czerwieni się jak ogien ${ }^{17}$.

18. Wiele jest odmian winorośli wysoce przydatnych do wyrobu wina. Jedną $z$ nich są winogrona aminnejskie (aminea), w nazwie których słyszymy niejako „bez cynobru” (sine minio) ${ }^{18}$, czyli bez czerwieni, bo otrzymuje się $\mathrm{z}$ nich białe wino ${ }^{19}$. Chociaż ma jedną nazwę, wydaje dwa rodzaje winogron - bliźniacze, zwane tak dla podwójnych kiści oraz włochate, pokryte bardziej niż inne siwym meszkiem. 19. Winogrona czerwonawe (rubilianae) otrzymały swoją nazwę od czerwonego koloru ich miąższu. Osadowe (feciniae) mają grona o małych jagodach i twardej skórce; szlachetnością ustępują, ale urodzajnością przewyższają aminnejskie. Zostały tak nazwane ponieważ dają więcej osadu (feces) niż inne ${ }^{20} .20$. Słodkie wino otrzymujemy $z$ winogron pszczelich

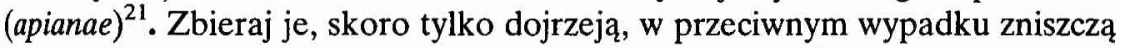
je wiatry, deszcze oraz pszczoły (apibus): te ostatnie czynią takie spustoszenie wśród winorośli tej odmiany, że została ona nazwana pszczelą (apiana). 21. Żołędziowe (balanitae) wzięły swą nazwę od wielkości, gdyż $\beta a ́ \lambda \alpha v o$ to po grecku żołędzie ${ }^{22}$. 22. Bituryckie (Biturica) zostały tak nazwane od regionu, w którym występują ${ }^{23}$ : są bardzo odporne na wichry, deszcze i upały, nie usychają też na jałowej ziemi ${ }^{24}$. Te same właściwości ma odmiana basilisca ${ }^{25}$. 23. Winorośl biała (argitis), to grecka winorośl rodząca białe jagody, urodzajna, o grubym krótkim pniu oraz szerokich liściach. Jej owoce powinny być natych-

${ }^{17}$ Por. Columella III 2, 1-2; André, Étymologies XVII 5, s. 56-57, n. 101.

${ }^{18}$ Zasługuje na uwagę nie spotykana więcej w XVI księdze Etymolodii grecko - lacińska etymologia tego wyrazu: a + minium.

${ }^{19}$ Była to jedna $z$ najbardziej cenionych w starożytności odmian winorosli, uprawiana powszechnie na południu półwyspu Apenińskiego. Jej nazwa pochodzi od miejscowości Aminei, która leżała na południe od dzisiejszego Salerno, por. André, Étymologies XVII 5, s. 57, n. 102; zob. także Mikołajczyk: Kolumella, O rolnictwie III 2, 7, I, s. 64.

${ }^{20}$ Nazwy rubella, rubellana i faecinia przysługiwały w rzeczywistości nomentańskiej odmianie winorosli, nazwanej tak od miejscowości Nomentum w Lacjum. Izydor jednak czyni z nich różne odmiany winogron, por. André, Étymologies XVII 5, s. 58, n. 104.

${ }^{21}$ Nazwą tą określano najprawdopodobniej winogrona muszkatolowe, por. Columella III 2 , 18; André, Etymologies XVII 5, s. 58, n. 105.

${ }^{22}$ Nikt poza Izydorem nie wspomina o istnieniu tej odmiany, por. André, Etymologies XVII 5, s. 59 , n. 106.

${ }^{23}$ Bituria to zamieszkana przez galijskie plemię Biturgów część Akwitanii, której głównym miastem były Biturigae (obecne Bourges), por. LTL V, Onomasticon, red. J. Perin, Prati 1871, 267; zob. także I. Dvoreckij, dz. cyt., s. 104. Inne nazwy geograficzne spotykane w tekście nie opatrujemy komentarzem, gdyż naszym zdaniem nie ma takiej konieczności - są one powszechnie znane (Libia, Rodos, Syria), czy też wyjaśnione przez Izydora (Mareocja).

${ }^{24}$ Por. Columella III 2, 19.

${ }^{25}$ Ta odmiana winorośli uprawiana była również w Hiszpanii, gdzie znano ja pod nazwą coccolobis. Jak zauważa J. André, jest zaskakujące, że Izydor o tym nie wspomina (Étymologies XVII 5, s. 59, n. 108). Być może, że jest to jeszcze jeden dowód na literacki charakter jego wiedzy ว roslinach? 
miast zebrane, inaczej opadną na ziemię i zgniją pod wpływem wilgoci ${ }^{26}$. 24. Winorośl inerticula jest czarna, Grecy zwą ją amaricion: daje dobre, lekkie wino, które zapewnilo jej taką nazwę, gdyż uważane jest za slabe (iners) w pobudzaniu nerwów, mimo że w smaku nie jest mdke ${ }^{27}$. 25 . Winogrona mareotyckie (Mareotica) zostały tak nazwane, ponieważ sprowadzono je kiedyś z regionu Egiptu - Mareocji: są one biale i czarne. 26. Winogrona elbolae, zwane przez niektórych mieniącymi się, nie są ani purpurowe ani czarne, ale żółtoróżowe (elbo) - stąd bierze początek ich nazwa - dają bowiem moszcz białawy. Żóltoróżowy (elbum) jest kolorem pośrednim między czarnym i białym, albowiem źółtoróżowy nie jest ani biały, ani czarny ${ }^{28}$.

27. Na trzecim miejscu są winorośle zasługujące na uwagę ze względu na urodzajność, <na przykład, elwennackie (elbennaca) $>^{29}$, przeobfite w grona i dające dużo wina. 28. Winorośl cionia ma grona raczej wielkie niż liczne, a nazwano ją tak dlatego, gdyż daje dużo wina ${ }^{30}$. Inną winorośl nazywają syryjską (Syriaca), a to dlatego, że sprowadzono ją z Syrii, czy też dlatego, że jest czarna ${ }^{31}$. 29. Liczne zaś są odmiany winorośli, które ze zmianą miejsca stracily zarówno nazwę, jak i właściwości.

30. Winorośli bardzo dobrze służą między innymi okopywanie, podcinanie, rozkrzewianie i przekopywanie. 31. Okopywanie (ablaqueare) polega na otwarciu ziemi wokól pnia i uczynieniu jakby zbiornika: niektórzy nazywają tę czynność excodicare. 32. Podcinanie (putare) sprowadza się do odcinania

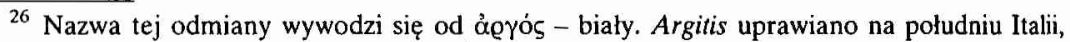
w tak zwanej Magna Graecia, por. André, Étymologies XVII 5, s. 60, n. 109; Columella III 2, 21..

${ }^{27}$ Por. Columella III 2, 24. Inerticula - to zdrobnienie od iners - slaby, tchórzliwy, gnuśny, leniwy, bezużyteczny. Chodzi więc o winorośl dającą wino smaczne, ale słabe, por. I. Dvoreckij, dz. cyt., s. 395; André, Étymologies XVII 5, s. 60, n. 110.

${ }^{28}$ Wartość chromatyczna przymiotników helvus (elbus) i helvolus (elbolus) wciąż pozostaje kwestią otwartą. Starożytni opisywali je jako kolory pomiędzy czerwonawym, rudym i białym; Izydor szuka początków elbus w albus (XIX 28, 7), pamiętajmy jednak, że w wypadku winogron biały nie jest bialym, ale jasnym, czarny nie jest do końca czarnym, lecz raczej ciemnym - granatowym, fioletowym, ciemnoczerwonym czy purpurowym. Tłumacze transliterują nazwę tej odmiany oraz przekładają helvus (elbus) jako płowy (I. Mikołajczyk), zóltawy (M. Plezia), różowy - rosé (J. André); rudy - rubio, bądź żółtawy - amarillento (J. Oroz Reta, M.A. Marcos Casquero); bladoróżowy - бледно-розобый, żółtawo - różowy - изжелта-розобый, ż́łty bursztynowy янтарно-жёлтый (I. Dvoreckij), por. Kolumella, dz. cyt., s. 71; por. Slownik lacińsko-polski, II, Warszawa 1973, 703; por. Étymologies, s. 60, n. 112; por. Etimologias, s. 332-333; por. także I. Dvoreckij, s. 360. Przyjmujemy żółtoróżowy, gdyż wydaje się nam, iż ten przymiotnik lączy w udany sposób odcienie znaczeniowe wszystkich poprzednich.

${ }^{29}$ Kolumella (III 2, 25) cytujący tu traktat Celsusa, zaznacza lakunę w jego tekście

${ }^{30}$ Manuskrypty zawierają różne nazwy tej odmiany, na przykład, spionia, scipionia, spioniosa.

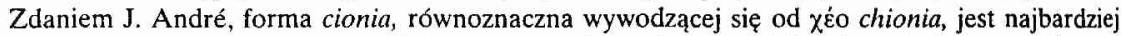
trafna, gdyż jej etymologia odpowiada wlaściwościom tej dającej dużo wina odmiany, por. Étymologies XVII 5, s. 62, n. 114.

${ }^{31}$ O tym, że przymiotnik syriacus może oznaczać nie tylko rubrus, lecz także niger pisal Serwiusz, por. André, Étymologies XVII 5, s. 63, n. 115. 
$\mathrm{z}$ winorośli zbytecznych gałęzi o bujnych odrostach. Obcinać (putare) bowiem znaczy tyle, co oczyszczać (purgare), czyli odcinać (amputare). Przeprowadzać (traducere) to przeciągać (transducere) ${ }^{32}$. 33. Rozkrzewianie (propaginare) natomiast dokonuje się przez rozpostarcie odrostu winorośli, przysypanie go ziemią i jakby zasadzeniu dalej (porro pangere). Stąd szczepy (propagines), nazwane tak od rozkrzewiania (propagare) i rozciągania (protendere). Kopać (fodere) natomiast to tyle co robić dół (fovea), niejako pielęgnować (fovere).

Z języka lacińskiego przełożyła, wstępem i komentarzem opatrzyła

Tatiana Krynicka - Lublin

\footnotetext{
${ }^{32}$ Przyjmuję wersję rekonstrukcji zaginionego tekstu zaproponowaną przez J. André, Étymologies XVII 5, s. 64.
} 